\title{
\begin{tabular}{l|l} 
Mitraries & DSpace@MIT
\end{tabular}
}

\author{
MIT Open Access Articles
}

\section{The Backseat Control Architecture for Autonomous Robotic Vehicles: A Case Study with the Iver2 AUV}

The MIT Faculty has made this article openly available. Please share how this access benefits you. Your story matters.

Citation: Eickstedt, D.P., and S.R. Sideleau. “The backseat control architecture for autonomous robotic vehicles: A case study with the Iver2 AUV." OCEANS 2009, MTS/IEEE Biloxi - Marine Technology for Our Future: Global and Local Challenges. 2009. 1-8.

Publisher: Institute of Electrical and Electronics Engineers

Persistent URL: http://hdl.handle.net/1721.1/59322

Version: Final published version: final published article, as it appeared in a journal, conference proceedings, or other formally published context

Terms of Use: Article is made available in accordance with the publisher's policy and may be subject to US copyright law. Please refer to the publisher's site for terms of use. 


\title{
The Backseat Control Architecture for Autonomous Robotic Vehicles: A Case Study with the Iver2 AUV
}

\author{
Donald P. Eickstedt and Scott R. Sideleau \\ Naval Undersea Warfare Center, Division Newport \\ Newport, RI 02421 \\ Email: donald.eickstedt@navy.mil; scott.sideleau@navy.mil
}

\begin{abstract}
In this paper, an innovative hybrid control architecture for real-time control of autonomous robotic vehicles is described as well as its implementation on a commercially available autonomous underwater vehicle (AUV). This architecture has two major components, a behavior-based intelligent autonomous controller and an interface to a classical dynamic controller that is responsible for real-time dynamic control of the vehicle given the decisions of the intelligent controller over the decision state space (e.g. vehicle course, speed, and depth). The driving force behind the development of this architecture was a desire to make autonomy software development for underwater vehicles independent from the dynamic control specifics of any given vehicle. The resulting software portability allows significant code reuse and frees autonomy software developers from being tied to a particular vehicle manufacturer's autonomy software and support as long as the vehicle supports the required interface between the intelligent controller and the dynamic controller. This paper will describe in detail the components of the backseat driver architecture as implemented on the Iver2 underwater vehicle, provide several examples of its use, and discuss the future direction of the architecture.
\end{abstract}

\section{INTRODUCTION}

Recent advances in autonomous underwater vehicle (AUV) technology have led to their use in a number of military and civilian applications including anti-submarine warfare, mine countermeasures, environmental sampling, and oilfield surveys among others. This increase in interest and funding has, predictably, led to an increase in the number of commercial companies offering AUVs. The number of commercial AUVs of all size classes as well as the number and types of sensors available for these AUVs has never been greater. Each of these companies, for understandable competitive reasons, has developed their own proprietary vehicle control software. Additionally, the major customers for some of these companies are oilfield survey operations which typically have a low interest in any sort of adaptive or cooperative vehicle maneuvering and, therefore, these companies have low interest in providing these capabilities as basic vehicle options. This situation has led to a disconnect with researchers developing applications requiring adaptive AUV autonomy who, for the most part, view underwater vehicles as commodity platforms designed to carry application-specific sensor suites. For this group, code portability and rapid reconfiguration on different vehicles is a major benefit.

This disconnect can be resolved by viewing intelligent vehicle control and dynamic vehicle control as being separable

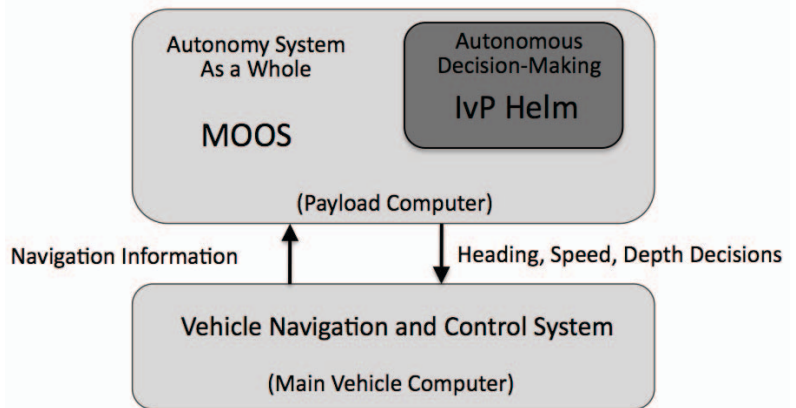

Fig. 1. The backseat driver architecture: The key idea is the separation of vehicle autonomy from vehicle control. The autonomy system provides heading, speed and depth commands to the vehicle control system. The vehicle control system executes the control and passes navigation information, e.g., position, heading and speed, to the autonomy system. The backseat paradigm is agnostic regarding how the autonomy system is implemented, but in this figure the MOOS-IvP autonomy architecture is depicted [1].

components of an overall vehicle control architecture. For our purposes, the intelligent control component is responsible for determining the proper decision over the state space of desired vehicle course, speed, and depth while the dynamic control component is responsible for obtaining and maintaining the desired state by manipulation of the actuator surfaces and thrusters as well as passing navigation information (e.g., position, heading and speed) to the autonomy system. The general architecture just described has been designated the backseat driver architecture [1] where the intelligent controller can be seen as residing in the backseat and the dynamic controller in the frontseat. In this arrangement, the dynamic controller typically resides on the manufacturer's main vehicle computer (MVC) and the intelligent controller may reside in a totally separate processor on the vehicle, communicating with the MVC via a network or serial link using a standard interface. Although this architecture can be used with any intelligent controller implementation, Fig. 1 shows it implemented using the MOOS-IvP autonomy system.

This approach allows the intelligent control software to be rapidly portable across many different vehicles with the only additional requirement being the need for an interface module that implements the backseat/frontseat interface for a particular vehicle. Although this paper is focused on the implementation of the backseat driver architecture on the Iver2 AUV, it should be noted that it has also been successfully implemented on the 
Bluefin 21, Hydroid Remus, and FAU Ocean Explorer AUVs.

The remainder of this paper will describe the implementation of the backseat control architecture on the Iver2 AUV manufactured by Ocean Server Technology based in Fall River, Massachusetts. Section II will describe the major components of the implementation including a detailed description of the Iver2 vehicle and the MOOS-IvP autonomy that supports the intelligent controller. Section III will describe the backseat control interface module that supports the interface between the intelligent controller and the MVC. Section V will show several vehicle runs made using the backseat control interface. The paper will conclude by discussing the need for a standardized backseat interface.

\section{System ARChiteCtURE}

In this section, we present the general system architecture for the Iver2 AUV equipped with the backseat driver architecture. This architecture consists of the Iver2 vehicle equipped with both a main vehicle computer supplied by the manufacturer as well as as a separate payload computer which hosts the intelligent controller running under the MOOS autonomy middleware [2]. In this implementation, the intelligent controller is the IvP Helm, a behavior-based helm that runs as a single MOOS process and uses multi-objective optimization with the Interval Programming (IvP) model for behavior coordination [3], [4]. The MOOS module iOceanServerComms (described in detail in Section III) provides the backseat/frontseat interface via a serial link with the MVC.

\section{A. The Iver2 AUV}

The Iver2 AUV (see Fig. 2) is a small man-portable AUV manufactured in Fall River Massachusetts by Ocean Server Technology, Inc. This vehicle was chosen by the Marine Autonomy Group (MAG) at the Naval Undersea Warfare Center in Newport, RI based primarily on the ability to rapidly launch the vehicle from shore or a variety of small or large craft as well as its ability to carry a variety of sensors relevant to our work in adaptive and collaborative autonomy. The vehicle's small size allows significantly more frequent experimental usage compared with larger vehicles needing ships with large capacity winches for launch and recovery. The MAG currently operates three Iver2 vehicles.

1) General Characteristics: The Iver2 vehicles in the MAG are approximately 65 inches in length and weigh approximately 50 pounds. The MAG vehicle is 5 inches longer than the standard vehicle and was lengthened to provide space for additional electronics including a precision clock, inertial measurement unit, and Iridium satellite transceiver. The vehicle can operate at speeds of up to 4 knots using its rechargeable batteries which have $600 \mathrm{Wh}$ of capacity. Vehicle endurance is anywhere between 4 and 12 hours depending on the vehicle's speed and hotel load (e.g. A/D conversion for the acoustic array). The vehicle also comes equipped with integrated depth (pressure) and altitude sensors.

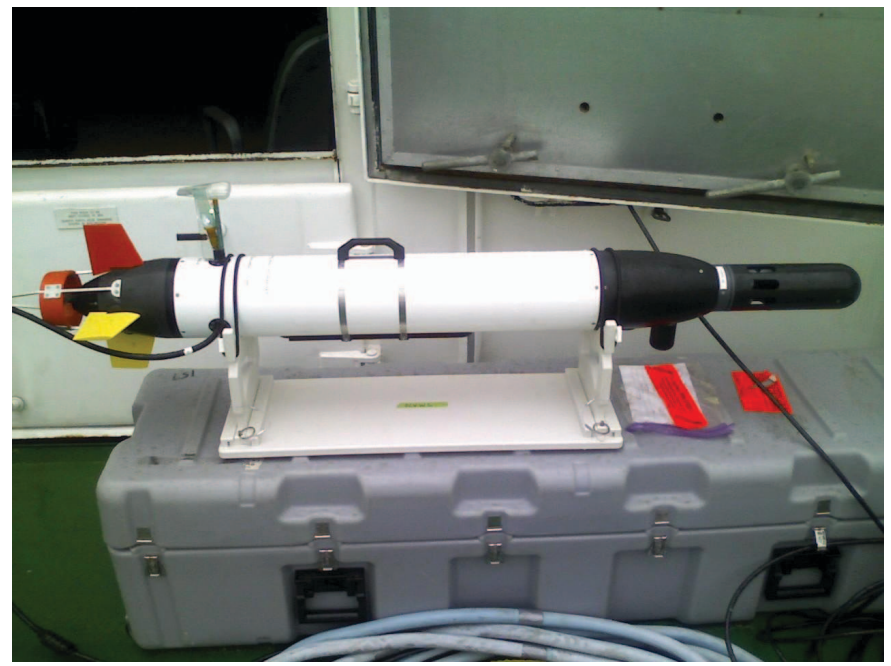

Fig. 2. The Iver2 AUV equipped with the YSI $6600 \mathrm{~V} 2$ sonde, Woods Hole Oceanographic Institute acoustic micromodem and a 16-element towed hydrophone array. The payload computer stack consists of a PIII-800 CPU and two 8 channel D/A boards. This model Iver2 navigates on the surface using GPS and underwater using a compass and speed table. This vehicle is designed for adaptive and collaborative autonomy experimentation applications including anti-submarine warfare and rapid environmental assessment.

2) Navigation: Each of the Iver2 vehicles in the MAG is equipped with a GPS receiver and three-axis digital compass providing roll, pitch, and yaw. One of the MAG vehicles was recently equipped with a Doppler velocity logger (DVL) to provide closed-loop speed control. The other two MAG vehicles have open-loop speed control using speed tables based on thruster RPM. Navigation solutions are computed on the MVC using dead reckoning and sent to the backseat over the backseat/frontseat interface. In the near future, all MAG vehicles will be equipped with inertial measurement units to provide closed-loop speed control in cases where the DVL is not equipped or cannot be used (e.g. in deep water).

3) Communications: Each of the Iver2 vehicles in the MAG is equipped with WiFi capability for communications while on the surface as well as a Woods Hole Oceanographic Institute acoustic Micromodem for communications while underwater. In the MAG configuration, the WiFi link is operated by the MVC and the acoustic modem is operated by the autonomy system on the payload computer. The acoustic modem is used both for providing status messages to the topside as well as for reception of command and control messages from the topside. In the near future, each MAG Iver2 will be equipped with an Iridium satellite transceiver which will provide status messages while the vehicle is on the surface as well provide for the reception of command and control instructions when the vehicle is out of $\mathrm{WiFi}$ or acoustic communications range.

4) Sensors: In the current MAG configuration, each Iver2 vehicle is equipped with a YSI, Inc. 6600V2-4 sensor bulkhead allowing the insertion of many different types of oceanographic sensor probes. The current MAG vehicles are equipped with conductivity-temperature, dissolved oxygen, and turbidity probes. Data from these probes is provided to the backseat 
autonomy system via the backseat interface in real time, allowing the vehicle to perform real-time adaptive environmental sampling. In addition to the oceanographic sensors, each vehicle is equipped with a 16-element acoustic line array cut for acoustic sampling at $1 \mathrm{KHz}$. Each array is equipped with inline preamplification. The array on each vehicle feeds acoustic data to a set of 8-channel analog to digital (A/D) converter boards described in II-A.5, allowing the vehicle to perform real-time underwater target tracking and localization experiments.

5) Payload Computer: The payload computer stack in the MAG Iver2 consists of a CPU board running an Intel PIII-800 processor with $512 \mathrm{MB}$ of main memory and a $100 \mathrm{~GB}$ hard drive. Communications with the MVC is via both a standard 10 Mbps Ethernet connection and a standard RS-232 serial link. The Ethernet link is primarily used for communication with the payload computer through the vehicle's WiFi connection while the serial connection is used for the backseat control interface. In addition to the CPU board, the payload computer stack is equipped with two General Standards 24DSI-12 8-channel A/D converter boards providing 16 channels of simultaneous sigma-delta sampling for the acoustic line array.

\section{B. The MOOS-IvP Autonomy Architecture}

The autonomy system on the MAG Iver2 vehicles is implemented within the MOOS-IvP architecture for autonomous control, developed and maintained under a GPL license by MIT, Oxford University, and NUWC. MOOS-IvP is composed of the Mission Oriented Operating Suite (MOOS), an open source software project for communication between, and nested control and coordination of, software processes running on the individual nodes of a network of autonomous platforms. MOOS-IvP is fully portable and platform independent, but typically implemented under GNU/Linux. MOOS-IvP also contains the IvP Helm, a behavior-based helm that provides the core of the behavior-based control architecture. The IvP Helm runs as a single MOOS process and uses multi-objective optimization with the Interval Programming (IvP) model for behavior coordination [3]. See [5], [6], and [7] for other examples of MOOS-IvP on autonomous marine vehicles.

A MOOS community contains processes that communicate through a database or bulletin board process called the MOOSDB , as shown in Fig. 3. The MOOSDB process is the core of the MOOS architecture and handles all communication between the processes using a publish-and-subscribe architecture. Thus, all processes may publish variable name/value pairs to the MOOSDB. Once a variable has changed, all processes that have registered for subscription to the variable will receive a notification, following which they may request the new variable value if needed. The MOOS processes include all necessary control functions as well as sensing and processing modules, with the MOOSDB providing the unified interface standard that enables the fully autonomous integration of sensing, modeling, processing, and control. MOOS ensures a process executes its Iterate method at a specified frequency and

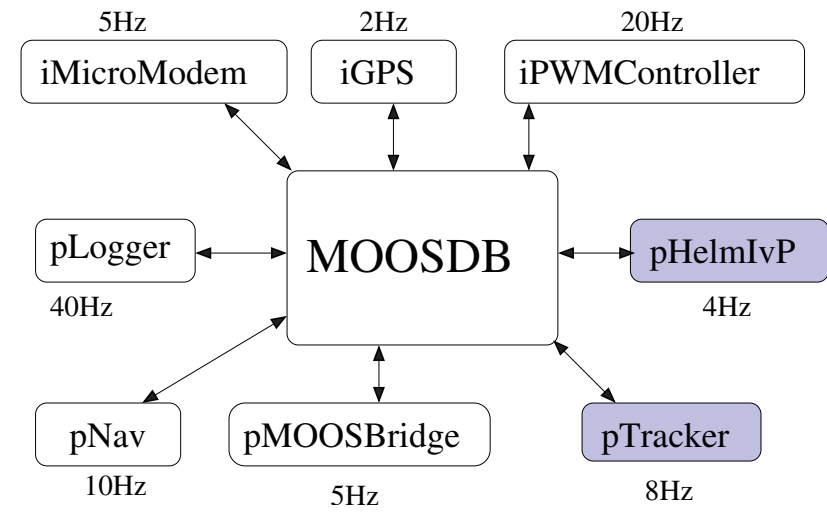

Fig. 3. A MOOS community contains processes that communicate through a database or bulletin board process called the MOOSDB. The MOOSDB process is the core of the MOOS architecture and handles all communication between the processes using a publish-and-subscribe architecture. MOOS may be composed of processes for data logging (pLogger), data fusion (pNav), actuation (iPWMController), sensing (iGPS), communication (pMOOSBridge, iMicroModem), and much more. They can all be run at different frequencies as shown.

handles new mail on each iteration in a publish and subscribe manner.

Each iteration of the helm contains the following steps: (1) mail is read from the MOOSDB, (2) information is updated for consumption by behaviors, (3) behaviors produce an objective function if applicable, (4) the objective functions are resolved to produce a single action, and (5) the action is posted to the MOOSDB for consumption by low-level control MOOS processes. This is illustrated in Fig. 4. Examples of

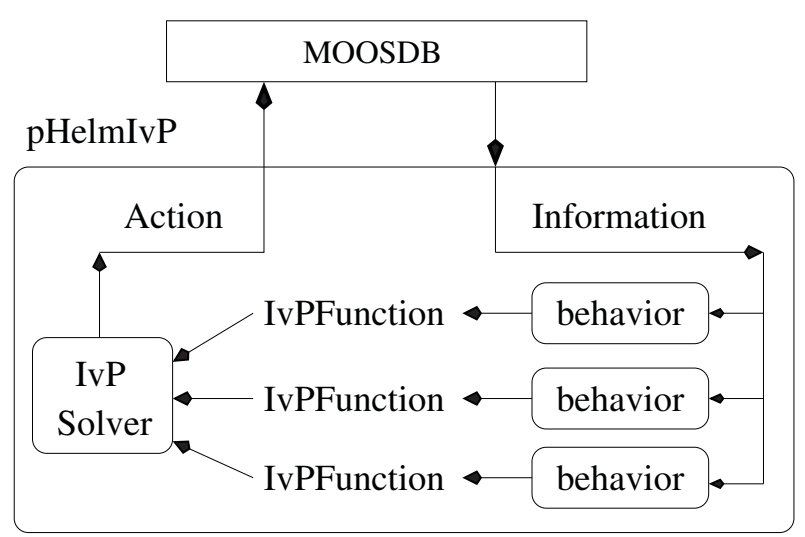

Fig. 4. The IvP Helm runs as a process called pHelmIvP in a MOOS community. On each iteration, pHelmIvP first uses information from the MOOSDB to compute an objective function over the decision state space of course, speed, and depth for each of the active behaviors. pHelmIvP then resolves these objective function into a single decision of desired vehicle course, speed, and depth. This decision is posted to the MOOSDB for consumption by the vehicle control system.

adaptive behaviors are described in [8]. Adaptive behaviors for oceanographic sampling with the autonomous kayaks are described in [9]. 


\section{The Backseat Control Architecture}

\section{A. Overview}

The iOceanServerComms MOOS module forms the interface between the main vehicle control system (i.e. MVC or frontseat) and the vehicle autonomy system (i.e. backseat). Regular updates from the vehicle's sensors (e.g. compass, GPS, altimeter, oceanographic sensors, etc.) received through the interface (as well as data received from sensors directly connected to the payload computer stack) are placed in the MOOS DB and are used by the IvP Helm to make decisions regarding the desired course, speed, and depth for the vehicle during the next control cycle. The desired course, speed, and depth are then transmitted by the iOceanServerComms module to the frontseat where the dynamic controller will attempt to maintain the desired vehicle state. Typically, this interface is run at a rate of one $\mathrm{Hz}$, which is sufficient to control a vehicle with a maximum speed of four knots. On the MAG Iver2 vehicles, the backseat/frontseat interface utilizes a standard RS-232 serial connection, resulting in the vehicle autonomy system appearing as another simple sensor to the vehicle dynamic control system. Other underwater vehicles such as the Bluefin 21 AUVs use Ethernet connections. Regardless of the connection method, the iOceanServerComms module is responsible for the transmission and processing of NMEAencoded messages over the interface. The following subsections will describe the contents of each message in detail. Full details are available in [10].

\section{B. Data Request Message}

The data request message (\$OSD) allows iOceanServerComms to request specific sensor messages from the frontseat. Because the MAG Iver2 vehicles are equipped with YSI 6600 oceanographic sensors (providing CTD [conductivity, temperature, depth], turbidity, and dissolved oxygen data), we can currently request updates of five different message types: compass, GPS, vehicle state, vehicle power (i.e. battery controller), and YSI sensors. The data request message is easily expandable by the vehicle manufacturer to facilitate data transmission from other sensors that require connectivity to the vehicle control system. For example, an Iver2 with an integrated Doppler velocity loggger for improved track line following or Inertial Measurement Unit for improved speed control should be capable of reporting each respective sensor's data in separate NMEA encoded strings. An example of the NMEA encoded string to request data from the Iver2 frontseat across a serial connection is shown in Table I where each of the five fields, if present as shown, indicates that message is requested from the frontseat.

In response to this message, the frontseat first replies with an acknowledgement (\$ACK) that the command was received and processed successfully or that the request was received and not processed due to an error. In response to the acknowledgement iOceanServerComms updates the MOOSDB variables FRONTSEAT_ACK and FRONTSEAT_ACK_ERROR which can be used for communications monitoring by the
TABLE I

DATA REQUEST MESSAGE

\begin{tabular}{|l|l|}
\hline \multicolumn{2}{|c|}{ \$OSD,C,G,S,P,Y*2A } \\
\hline SOSD & Message header \\
\hline C & Compass request \\
\hline G & GPS request \\
\hline S & State (of vehicle) request \\
\hline P & Power (or battery controller) request \\
\hline Y & YSI Sensor request \\
\hline$\star 2 \mathrm{~A}$ & $\begin{array}{l}\text { Standard NMEA checksum } \\
\text { (XOR of message contents) }\end{array}$ \\
\hline
\end{tabular}

end user or an intermediate MOOS application. If successful, the frontseat then transmits the requested data messages. If a particular message fails the checksum test when decoded by the iOceanServerComms module, it is then discarded. Currently, iOceanServerComms requests and parses all five NMEA messages (six including \$ACK) per data request on the MAG Iver2 vehicles. The data polling rate on the MAG vehicles is is one $\mathrm{Hz}$, but frequencies of up to $20 \mathrm{~Hz}$ have been tested on the bench and/or in the water. The user must balance the density of data to post-process and the size of the $\log$ files generated when considering the rate of data polling.

The iOceanServerComms module parses the NMEA messages and updates the appropriate MOOS variables as described in Tables II through VII. To allow for intermediate manipulation by other MOOS processes and to facilitate the use of other sensors that may be more accurate on the reporting of particular data (e.g. heading), iOceanServerComms does not directly post to the MOOSDB certain critical navigation variables that the IvP Helm monitors. Instead, iOceanServerComms publishes data to unique MOOS variables and requires that the user employ the MOOS utility module pEchoVar to re-post data to the correct variables. This method allows, for example, data from an IMU to be posted to the NAV_HEADING variable instead of the COMPASS_HEADING from the frontseat to be posted to the NAV_HEADING variable. On the MAG Iver2 vehicles, pEchoVar currently re-posts the variables published by iOceanServerComms as shown in Table II.

TABLE II

ECHOED VARIABLES

\begin{tabular}{|l|l|}
\hline Published by iOceanServerComms & Published by pEchoVar \\
\hline COMPASS_HEADING & NAV_HEADING \\
\hline COMPASS_DEPTH & NAV_DEPTH \\
\hline COMPASS_PITCH & NAV_PITCH \\
\hline COMPASS_ROLL & NAV_ROLL \\
\hline COMPASS_YAW & NAV_YAW \\
\hline FRONTSEAT_X & NAV_X \\
\hline FRONTSEAT_Y & NAV_Y \\
\hline FRONTSEAT_LAT & NAV_LAT \\
\hline FRONTSEAT_LONG & NAV_LONG \\
\hline FRONTSEAT_SPEED & NAV_SPEED \\
\hline
\end{tabular}




\section{Received Sensor Messages}

The following subsections describe the individual MOOS variables that iOceanServerComms updates when receiving a given sensor message.

1) Compass Message: The $\$ C$ message from vehicle control system's navigational compass populates the MOOS variables as shown in Table III.

TABLE III

Compass Message

\begin{tabular}{|l|l|}
\hline Published by iOceanServerComms & \multicolumn{1}{c|}{ Purpose } \\
\hline COMPASS_YAW & Magnetic heading (degrees) \\
\hline COMPASS_PITCH & Vehicle pitch (degrees) \\
\hline COMPASS_ROLL & Vehicle roll (degrees) \\
\hline COMPASS_TEMPERATURE & Ambient temperature (degrees C) \\
\hline COMPASS_DEPTH & Vehicle depth (feet) \\
\hline COMPASS_HEADING & Calculated true heading (degrees) \\
\hline
\end{tabular}

2) GPS Message: The \$GPRMC message from the vehicle control system populates the MOOS variables shown in Table IV when a stable satellite fix is present.

TABLE IV

GPS MESSAGE

\begin{tabular}{|l|l|}
\hline Published by iOceanServerComms & \multicolumn{1}{|c|}{ Purpose } \\
\hline GPS_TIME & UTC time of day \\
\hline GPS_WARNING & Satellite fix good? \\
\hline GPS_SPEED & Estimated vehicle speed (m/s) \\
\hline GPS_HEADING & True heading (degrees) \\
\hline GPS_DATE & UTC date \\
\hline GPS_MAGNETICVARIATION & Magnetic variation (degrees) \\
\hline GPS_LATITUDE & Latitude (decimal degrees) \\
\hline GPS_LONGITUDE & Longitude (decimal degrees) \\
\hline GPS_UPDATE_RECEIVED & Time of last valid fix \\
\hline
\end{tabular}

3) State Message: The $\$$ OSI message from the vehicle control system populates the MOOS variables as shown in Table V.

TABLE V

State Mess AGE

\begin{tabular}{|l|l|}
\hline Published by iOceanServerComms & \multicolumn{1}{|c|}{ Purpose } \\
\hline FIN_T_YAW & Top fin's yaw (servo setting) \\
\hline FIN_B_YAW & Bottom fin's yaw (servo setting) \\
\hline FIN_L_PITCH & Left fin's pitch (servo setting) \\
\hline FIN_R_PITCH & Right fin's pitch (servo setting) \\
\hline FIN_MOTOR_SPEED & Motor thrust (servo setting) \\
\hline IVER_FRONTSEAT_WP & Frontseat mission's waypoint \\
\hline FRONTSEAT_LAT & GPS or DR Latitude \\
\hline FRONTSEAT_LONG & GPS or DR Longitude \\
\hline FRONTSEAT_SPEED & Vehicle speed (knots) \\
\hline FRONTSEAT_X & Vehicle X MOOS coordinate \\
\hline FRONTSEAT_Y & Vehicle Y MOOS coordinate \\
\hline
\end{tabular}

4) Power Message: The \$OPI message from the vehicle control system's battery controller populates the MOOS variables as shown in Table VI.

TABLE VI

Power Message

\begin{tabular}{|l|l|}
\hline Published by iOceanServerComms & \multicolumn{1}{c|}{ Purpose } \\
\hline BATTERY_PERCENT & Percent charge remaining \\
\hline BATTERY_WATTHRS & Watt-hours remaining \\
\hline BATTERY_WATTS & Wattage draw \\
\hline BATTERY_VOLTS & Voltage level \\
\hline BATTERY_AMPS & Current draw \\
\hline BATTERY_TIME & Time to empty/full \\
\hline BATTERY_STATE & Charging or discharging? \\
\hline BATTERY_LEAK & Leak detection Boolean \\
\hline
\end{tabular}

5) Oceanographic Sensor Message: The \$YSI message from the vehicle control system's YSI 6600V2 oceanographic sensor payload populates the MOOS variables as shown in Table VII.

TABLE VII

THE YSI MESSAGE

\begin{tabular}{|l|l|}
\hline Published by iOceanServerComms & \multicolumn{1}{c|}{ Purpose } \\
\hline YSI_DATE2 & Date of YSI controller \\
\hline YSI_TIME & Time of YSI controller \\
\hline YSI_TEMP & Temperature (degrees C) \\
\hline YSI_SPCOND & Specific conductivity $(\mathrm{mS} / \mathrm{cm})$ \\
\hline YSI_SALINITY & Salinity $(\mathrm{ppt})$ \\
\hline YSI_DEPTH & Depth $(\mathrm{m})$ \\
\hline YSI_TURBIDITY & Turbidity $(\mathrm{NTU})$ \\
\hline YSI_ODO & Percent dissolved oxygen \\
\hline YSI_ODO & Dissolved oxygen (mg/L) \\
\hline YSI_BATTERY & Voltage of YSI controller \\
\hline CTD_SOUND_VELOCITY & Calculated sound velocity \\
\hline
\end{tabular}

\section{Helm Control Variables}

The IvP Helm calculates the objective functions of the active helm behaviors and makes a decision on the desired vehicle course, speed, and depth for the next control cycle. The helm then updates the variables in the MOOS DB shown in Table VIII.

TABLE VIII

HELM CONTROL VARIABLES

\begin{tabular}{|l|l|}
\hline Published by pHelmIvP & \multicolumn{1}{c|}{ Units } \\
\hline DESIRED_HEADING & degrees true \\
\hline DESIRED_SPEED & meters/sec \\
\hline DES IRED_DEPTH & meters \\
\hline
\end{tabular}

When the IvP Helm has control (i.e. the MOOS variable MOOS_MANUAL_OVERRIDE = FALSE), iOceanServerComms reads these variables and transmits the NMEA-encoded \$OMS message to the frontseat as shown in Table IX. 
TABLE IX

BaCKSEAT CONTROL MESSAGE

\begin{tabular}{|l|l|}
\hline \multicolumn{2}{|c|}{ \$OMS,H,D,A,S,T*CC } \\
\hline \$OMS & Message header \\
\hline H & Desired heading \\
\hline D & Desired depth (feet) \\
\hline A & Maximum pitch angle \\
\hline S & Desired speed (knots) \\
\hline T & Desired timeout (sec) \\
\hline$\star C C$ & $\begin{array}{l}\text { Standard NMEA checksum } \\
\text { (XOR of message contents) }\end{array}$ \\
\hline
\end{tabular}

The maximum dive/surface angle, for safety reasons, is set to the Ocean-Server recommendation of 30 degrees by iOceanServerComms. The backseat timeout, or when the frontseat control system should take control of the vehicle after not receiving a new \$OMS message, is configurable via a parameter in the iOceanServerComms module configuration file.

The backseat continues to transmit \$OMS messages as long as the IvP Helm is engaged (MOOS variable IVPHELM_ENGAGED = ENGAGED). The iOceanServerComms module monitors the status of IVPHELM_ENGAGED and also notes the time the last update was received. If the configurable timeout is reached before an update to IVPHELM_ENGAGED is received, iOceanServerComms assumes the IvP Helm process has relinquished control or has stopped due to an unexpected error and blocks the further sending of servo control messages until another update to IVPHELM_ENGAGED is received. Control may also be released by iOceanServerComms when the IvP Helm reports it has completed executing all of its autonomy behaviors (IVPHELM_ENGAGED = DISENGAGED); for example, after a backseat mission timeout has occurred. When disengaged, the frontseat control system continues to execute the last received heading, depth, and speed until the frontseat timeout (specified in the \$OMS message itself) expires. Then, the frontseat control system resumes control and finishes execution of its pre-programmed mission (e.g. to park the vehicle at a desired location).

\section{E. Primitive Control Message}

The Ocean-Server \$OMP message allows the backseat autonomy system to directly control the fin and propulsion settings of the vehicle. Although arguably antithetical to the backseat driver control philosophy, this enables the development of a custom dynamic controller and navigation fusion MOOS module that, in turn, facilitates control of a heavily modified Iver2 vehicle (i.e. one which no longer matches an existing frontseat control profile). The primitive control message (see Table $\mathrm{X}$ ) requires the population of the MOOS variables shown in Table $\mathrm{X}$ to produce a valid \$OMP message. The \$OMP message follows the same timeout rules as the \$OMS message.
TABLE X

Primitive Control Mess Age

\begin{tabular}{|l|c|}
\hline Subscribed to by iOceanServerComms & Units \\
\hline DESIRED_RUDDER & servo control value $(0-255)$ \\
\hline DESIRED_ELEVATOR & servo control value $(0-255)$ \\
\hline DESIRED_THRUST & servo control value $(0-255)$ \\
\hline
\end{tabular}

\section{OpERATIONAL SAFETY}

This section outlines the operational safety employed in the deployment of the MAG Iver2 vehicles. Safety rules can be activated on either the frontseat or backseat payload computers, with the triggering of backseat safety rules resulting in the relinquishment of vehicle control to the frontseat. The safety rules run in the IvP Helm are considered the primary safety rules with the rules run on the frontseat considered to be emergency backup in case of a backseat failure. In addition to exploring safety in software, hardware accessories are also described.

\section{A. Backseat Safety}

In addition to the IvP Helm monitoring that iOceanServerComms provides (see III), the use of the operating region behavior (BHV_OpRegion) is used to provide the IvP Helm with a three-dimensional zone of operation and maximum mission time. If the vehicle exceeds the operating region bounds or the maximum mission time, the IvP Helm commands the vehicle to a heading, depth, and speed of zero and then disengages (IVPHELM_ENGAGED = DISENGAGED). After the configurable iOceanServerComms timeout has expired, control is relinquished to the frontseat computer, where the pre-programmed mission (e.g. to park the vehicle) is executed.

\section{B. Frontseat Safety}

The Ocean-Server Technology frontseat control software, Underwater Vehicle Controller (or UVC), enables the operator to set a number of safety rules, including:

- Maximum depth from surface

- Minimum depth off bottom

- Maximum mission time

- Maximum dive angle over time

- Detection of no forward progress

- Detection of no upward progress when surfacing

- Detection of no downward progress when diving

- Leak detection

If an enabled safety rule triggers, then the frontseat controller aborts its current mission, stops processing servo (\$OMS) and primitive (\$OMP) commands from the backseat driver, and executes its safety return path mission, which is a series of surface waypoints previously designed to park the vehicle at a safe location on the surface where it can then be retrieved.

The frontseat safety rules should always take precedence over any backseat driver operations as the backseat autonomy is, again, only a "sensor" to the vehicle control computer. 


\section{Accessories}

The MAG Iver2 vehicles are all equipped with Sonotronics EMT-01-2 to facilitate vehicle recovery in the event that the vehicle remains underwater beyond the mission execution time (e.g. vehicle becomes entangled or otherwise stuck).

Ocean-Server Technology, Inc. also provides a safety tow float option (patent pending), which is a small towed device capable of deploying a programmable buoyancy airbag to bring the vehicle to the surface. The MAG Iver2 vehicles will be equipped with these safety tow floats, in the near future, when completing operations that do not require the use of their towed arrays.

\section{Results}

This section will illustrate several backseat driver missions executed on the MAG Iver2 vehicle using the iOceanServerComms backseat driver interface module running under MOOS-IvP, one simple fixed pattern mission as well as an adaptive sampling mission. Fig. 5 and Fig. 6 show a recent hexagonal loiter mission run by the MAG Iver2 on the Charles River in Boston. The mission goal is for the vehicle to transit to the operations area, run a hexagonal loiter pattern at a one meter depth, and then return to and park at the starting location. As can be seen in the plot of the vehicle position (Fig. 5), this mission was successfully completed. The distortion in the shape of the hexagon is because of the relatively inaccurate navigation due to the use of open-loop speed control. The acquisition of a Doppler Velocity Logger (DVL) for closed-loop speed control is expected to greatly increase the navigational accuracy of the vehicle. The depth of the vehicle during the mission is shown in Fig. 6. As can be seen in the plot, the vehicle maintains its commanded one meter depth except when the periodic surface behavior forces the vehicle to surface for a GPS fix.

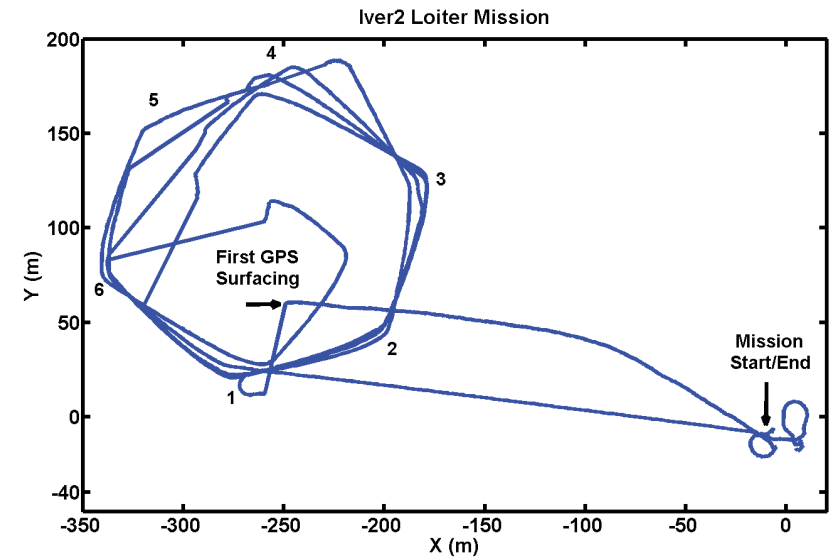

Fig. 5. A simple hexagonal loiter backseat mission run by the Iver2 on the Charles River. The distortion in the shape of the hexagon is because of the relatively inaccurate navigation due to the use of open-loop speed control. The acquisition of a Doppler velocity logger (DVL) for closed-loop speed control is expected to greatly increase the navigational accuracy of the vehicle.

Fig. 7 shows a plot of a more complicated adaptive sampling mission. The mission goal for the vehicle is to run horizontally

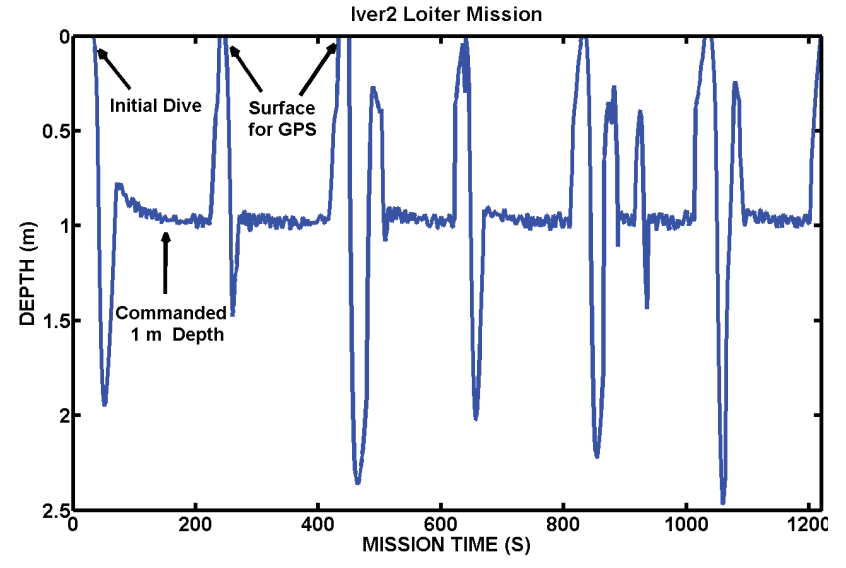

Fig. 6. A plot of the Iver2 depth during the hexagonal loiter backseat mission on the Charles River. As can be seen in the plot, the vehicle maintains its commanded one meter depth except when the periodic surface behavior forces the vehicle to surface for a GPS fix.

in a fixed direction while changing its depth adaptively to try and capture the thermocline. This mission was run in 80 meters of water in the Mediterranean off of Pianosa Island in August, 2008. As shown in the plot, the vehicle first samples the entire water column to gather statistics on the sound speed profile and then adaptively changes the yoyo depth to focus sampling on the thermocline which was at approximately 10 meters depth.

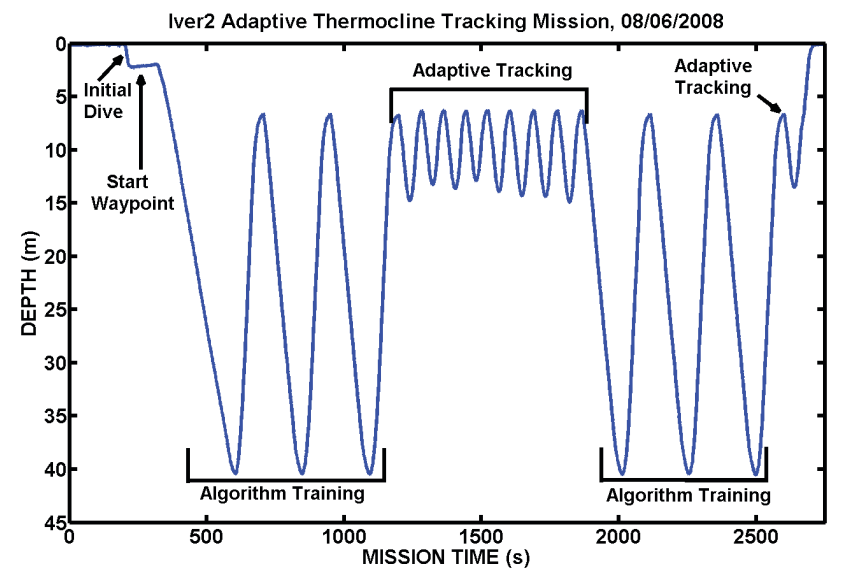

Fig. 7. A plot of the Iver2 depth during an an adaptive thermocline tracking mission in the Mediterranean off of Pianosa Island in August, 2008. As shown in the plot, the vehicle first samples the entire water column to gather statistics on the sound speed profile and then adaptively changes the yoyo depth to focus sampling on the thermocline which was at approximately 10 meters depth.

\section{CONCLUSION}

In this paper we have described the backseat driver architecture for robotic vehicles in detail and its implementation on a commercially available autonomous underwater vehicle. Although this architecture was developed for marine vehicles, it is also usable on other types of vehicles such as land or aerial robots. The driving force behind the development of this architecture was a desire for a high degree of autonomy software code reuse among different marine vehicles. In fact, 
we estimate that code reuse is over $90 \%$ as the vast majority of MOOS-IvP modules are reused on the Iver2, Bluefin 21, FAU Ocean Explorer, and Hydroid Remus vehicles.

One issue that needs to be addressed, and is being addressed at NUWC, is the development of a standard for the backseat driver interface including message formats and interface handshake protocols. Even though all the vehicles mentioned have a backseat driver interface, each manufacturer has implemented its own message format and interface control protocols. An interface standard would allow for rapid development of interface modules for new vehicles as well as increase code portability and reuse of the autonomy modules. A draft backseat driver interface standard is currently under development by the MAG and is expected to be completed by the end of 2009.

\section{ACKNOWLEDGEMENTS}

The authors would like to acknowledge the staff at Ocean Server Technology, Inc. as well as Dr. Mike Benjamin for their assistance in the development and testing of the backseat driver interface for the Iver2 vehicle.

\section{REFERENCES}

[1] M. R. Benjamin, P. M. Newman, H. Schmidt, and J. J. Leonard, "A Tour of MOOS-IvP Autonomy Software Modules," MIT Computer Science and Artificial Intelligence Lab, Tech. Rep. MIT-CSAIL-TR-2009-009, February 2009.

[2] P. Newman, Under the Hood of the MOOS Communications API, Oxford University, 2009.

[3] M. R. Benjamin, "Interval Programming: A Multi-Objective Optimization Model for Autonomous Vehicle Control," Ph.D. dissertation, Brown University, Providence, RI, May 2002.

[4] M. R. Benjamin and J. Curcio, "COLREGS-Based Navigation in Unmanned Marine Vehicles," in AUV-2004, Sebasco Harbor, Maine, June 2004.

[5] M. Benjamin, J. Curcio, J. Leonard, and P. Newman, "Navigation of Unmanned Marine Vehicles in Accordance with the Rules of the Road," in International Conference on Robotics and Automation (ICRA), Orlando, Florida, May 2006.

[6] M. Benjamin, M. Grund, and P. Newman, "Multi-objective Optimization of Sensor Quality with Efficient Marine Vehicle Task Execution," in International Conference on Robotics and Automation (ICRA), Orlando, Florida, May 2006.

[7] M. R. Benjamin, D. Battle, D. P. Eickstedt, H. Schmidt, and A. Balasuriya, "Autonomous Control of an Autonomous Underwater Vehicle Towing a Vector Sensor Array," in IEEE International Conference on Robotics and Automation, Rome, Italy, April 2007, pp. 4562-4569.

[8] D. Eickstedt, M. Benjamin, H. Schmidt, and J. Leonard, "Adaptive Control of Heterogeneous Marine Sensor Platforms in an Autonomous Sensor Network," in Proceedings of the 2006 IEEE/RSJ Int. Conf. on Intelligent Robots and Systems, Beijing, China, October 2006.

[9] D. P. Eickstedt, M. R. Benjamin, D. Wang, J. Curcio, and H. Schmidt, "Behavior Based Adaptive Control for Autonomous Oceanographic Sampling," in IEEE International Conference on Robotics and Automation, Rome, Italy, April 2007, pp. 4245-4250.

[10] J. DeArudda and J. Crowell, Remote Helm Guide, Ocean Server Technology, Inc., 2009. 